\title{
Lavdoserate brakyterapi ved lavgradig prostatakreft
}

\begin{abstract}
BAKGRUNN Prostatakreft er en strålefølsom krefttype der ekstern strålebehandling benyttes i både kurativt og palliativt øyemed. Lavdoserate brakyterapi er en innvendig strålebehandlingsteknikk som tillater å gi høye stråledoser med høy presisjon og kort rekkevidde i et tumorvolum. Vi har systematisk gjennomgått kunnskapsgrunnlaget for en slik behandling. Metoden er ikke etablert i Norge.
\end{abstract}

KUNNSKAPSGRUNNLAG Denne oversikten bygger på systematiske oversiktsartikler og publikasjoner om behandling, effektmål, bivirkninger og helseøkonomiske vurderinger etter søk i databasene The Cochrane Library, Current Controlled Trials, Medline, Embase og NICE (National Institute for clinical excellence).

RESULTATER Basert på langtidsobservasjoner av effekt, bivirkninger og kostnader presentert i 43 selekterte studier, deriblant én randomisert, kontrollert studie, er det fremdeles usikkerhet omkring hvilken metode som er best når man sammenlikner lavdose brakyterapi, ekstern strålebehandling og radikal prostatektomi. Årsaken er metodiske forskjeller i pasientutvalg og effektestimater, som PSA-fritt intervall og prostataspesifikk overlevelse. Kunnskapsgrunnlaget kan tyde på at lavdoserate brakyterapi gir hyppigere legerapporterte urogenitale bivirkninger grad 2 og grad 3 sammenliknet med prostatektomi, men bedre pasientrapporterte seksuelle funksjoner og færre pasienter med urininkontinens enn etter kirurgi. Lavdoserate brakyterapi synes å være samfunnsmessig kostnadsbesparende.

FORTOLKNING Kunnskapsgrunnlaget med henblikk på behandlingseffekt og toksisitet hos menn med lavrisiko prostatakreft som behandles med lavdoserate brakyterapi anses som solid dokumentert. Det mangler imidlertid gode prospektive randomiserte multisenterstudier med totaloverlevelse som endepunkt.

Prostatakreft er den vanligst forekommende kreftsykdom hos menn i Norge, og i 2011 var det 4978 som fikk diagnosen (1). Prostatektomi og strålebehandling er de to eneste behandlingsmodaliteter som internasjonalt anses å ha kurativt potensial ved lokalisert sykdom. Til tross for forbedringer både diagnostisk og behandlingsmessig er mortaliteten i Norge ikke tilsvarende redusert (2). Prognosen er relatert til flere kliniske faktorer: primærtumorens utbredelse (T-stadium), prostataspesifikt antigen (PSA) og tumors grad av differensiering og aggressivitet (Gleason-skår). Ut fra disse faktorene klassifiseres pasientene i tre prognostiske risikogrupper (lav, intermediær, høy).

Hos pasienter med lavrisikosykdom utvikler den seg som regel svært langsomt, og det er liten risiko for spredning. Pasientene har gunstige sykdomsvariabler, klassifisert som $\leq \mathrm{T} 2 \mathrm{a}$, PSA $<10$ ug/1 og Gleason-skår $\leq 6$. Siden PSA-screeningen øker, vil insidensen av prostatakreft med lav risikoprofil øke i årene fremover. Disse pasientene er ikke nødvendigvis umiddelbart behandlingstrengende. Mange kan ha stabil, asymptomatisk sykdom i mange år og kan inkluderes i et kontrollopplegg kalt «aktiv overvåking». Man antar at ca. 30\% av pasienter som overvåkes senere vil trenge behandling (3). Indikasjon for behandling er gjerne stadig sti- gende PSA-nivå og/eller en mer aggressiv Gleason-skår.

Enkelte ønsker imidlertid ikke å bli fulgt ubehandlet med en kreftdiagnose selv om sykdommen er stabil uten sykdomsprogrediering. Dersom slike pasienter skal behandles, bør metoden være effektiv og ha færrest mulig bivirkninger. Ultralydveiledet implantasjon av permanente radioaktive jodkorn (I-125) transperinealt inn i prostatakjertelen (lavdoserate brakyterapi - LDRBT) er en metode som brukes i mange land hos disse pasientene (fig 1).

Ekstern strålebehandling (EBRT) blir tradisjonelt gitt med flerfeltsteknikk fra en ekstern kilde og med daglige fraksjoner à 2 Gy (Gy er symbol for gray, enhet for absorbert stråledose) fem dager per uke til totaldose 74-78 Gy over omtrent åtte uker. Alternativt kan det utføres åpen eller robotassistert radikal kirurgi (PRECT)

Lavdoserate brakyterapi, eller innvendig bestråling, er en høyteknologisk behandlingsprosedyre som tillater avsetning av svært høye kumulative stråledoser med kort rekkevidde i prostata (braky er gresk for kort), mens stråledosen som blir avsatt utenfor blir betydelig redusert. Stråledosen fra jodkornene avsettes gradvis i prostata i løpet av omtrent to måneder (fig 2)

Ved høydoserate brakyterapi (HDR-BT),
Nils Kristian Raabe CC-Vest legesenter Oslo

\section{Marius Normann}

Kreftsenteret Aleris Helse

Oslo

\section{Wolfgang Lilleby}

wolfgang.lilleby@ous-hf.no

Onkologisk avdeling

Oslo universitetssykehus, Radiumhospitalet

Se også kunnskapsprøve

på www.tidsskriftet.no/quiz

Engelsk oversettelse på www.tidsskriftet.no

> Se lederartikkel side 508

\section{HOVEDBUDSKAP}

Langtidsresultatene etter lavdoserate brakyterapi med vekt på PSA-fritt intervall og prostataspesifikk overlevelse er ekvivalente med prostatektomi og ekstern strålebehandling

Ereksjonssvikt og pasientrapportert urinlekkasje synes å være redusert sammenliknet med prostatektomi og ekstern strålebehandling

Metoden synes å være kostnadseffektiv 


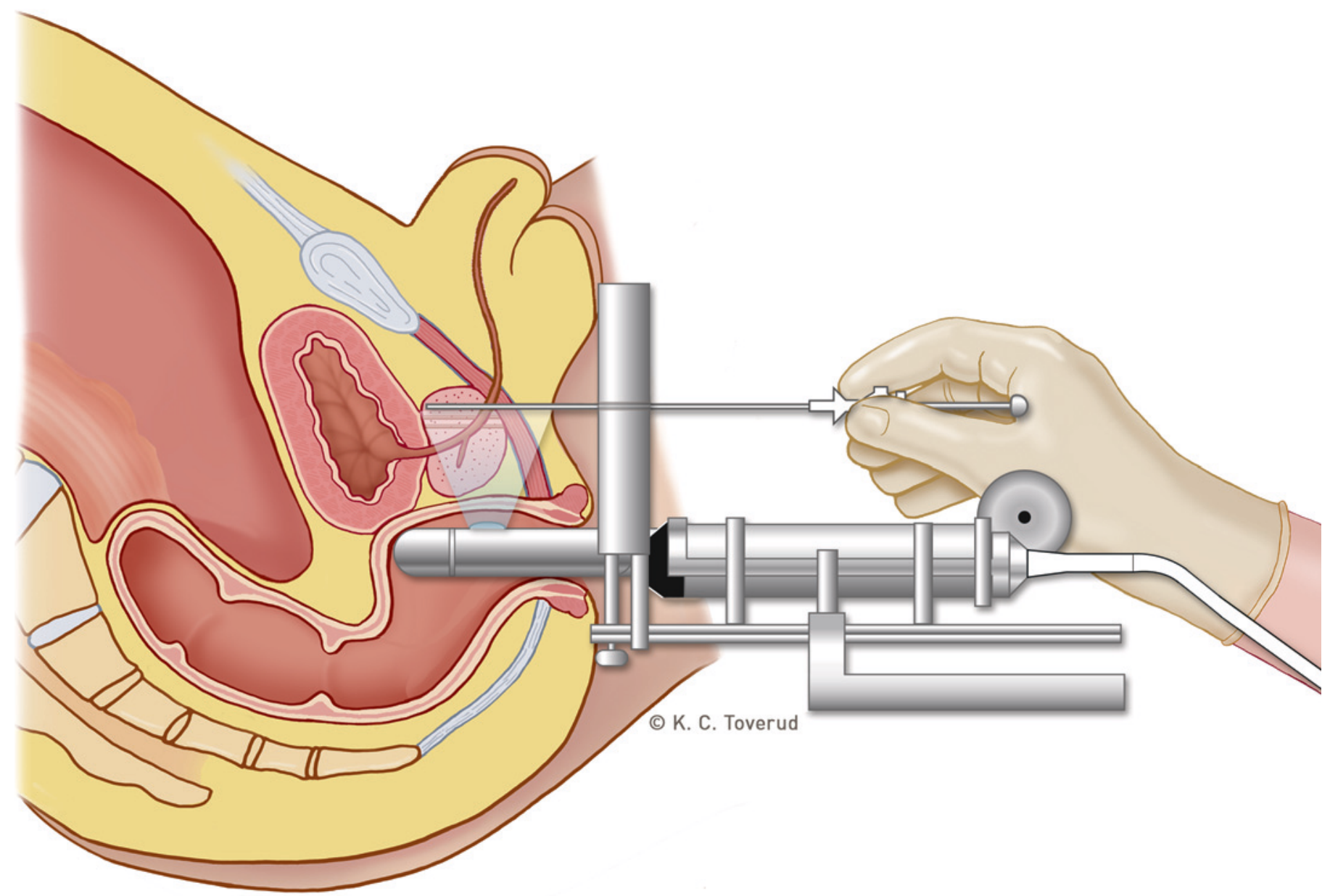

Figur 1 Lavdoserate brakyterapi med transrektal ultralydveiledning. Transperineal implantasjonsteknikk av radioaktive jodkorn (I-125) gjennom en perforert plate (templat) med koordinatsystem for presis deponering av jodkornene i prostata

som anvendes hos pasienter med intermediær og høy risikoprofil, implanteres hule stålnåler inn i prostatakjertelen. Etter tur introduseres en radioaktiv kilde (192-iridium) temporært inn i kjertelen gjennom nålene (4).

Internasjonalt har man over 25 års erfaring med lavdoserate brakyterapi. Omtrent en tredel av pasientene i USA med lavrisikosykdom, ca. 50 000, behandles med denne metoden hvert år. Norge er det eneste land i Nord-Europa hvor metoden ikke er tilgjengelig. I denne oversiktsartikkelen gjennomgår vi effekt, bivirkninger og kostnadseffektivitet ved behandlingsformen.

\section{Kunnskapsgrunnlag}

Vi har søkt etter artikler på engelsk, tysk eller skandinaviske språk publisert fra primo januar 2000 til medio desember 2013 i følgende databaser: the Cochrane Library, Current Controlled Trials, Medline, Embase og NICE. I de to førstnevnte ble det gjort et enkelt søk etter henholdsvis oversiktsartikler og pågående studier av prostatakreft med lavdoserate brakyterapi.
I databasene Medline og Embase ble følgende søkestreng brukt: (prostate tumor AND brachytherapy AND (low dose rate or LDR) kombinert med (survival analysis/or disease-free survival OR treatment outcome/or treatment failure OR survival OR brachytherapy/adverse effects OR radiation injuries OR quality of life). Senter for medisinsk metodevurdering (SMM), NICE-instituttet og Cochrane Library ble brukt for innspill på helseøknomiske betraktninger.

\section{Inklusjon av studier}

I alt 219 artikler oppfylte søkekriteriene. 176 artikler som omhandlet lavdoserate brakyterapi i kombinasjon med radikal kirurgi eller ekstern strålebehandling ble ekskludert. Denne artikkelen er dermed basert på 43 artikler som omhandler lavdoserate brakyterapi som monoterapi: én randomisert, kontrollert studie, 30 ikke-randomiserte observasjonsstudier, sju oversiktsartikler som er basert på diverse enkeltstudier samt fem helseøkonomiske artikler.

I tabell 1 (5-16) presenteres langtidsresul- tatene av lavdoserate brakyterapi i 12 studier der mer enn 100 pasienter var inkludert.

\section{Evaluering av studier}

For bedømmelse av kvalitet i studiene har vi brukt et valideringssystem anbefalt av Helsedirektoratets kunnskapssenter, det er også benyttet $\mathrm{i}$ de nasjonale retningslinjene for behandling av prostatakreft (17). Vi har lagt vekt på endepunkter som PSA-fritt intervall (tidsintervall mellom behandling og evalueringstidspunkt uten PSA-stigning), PSA-fri overlevelse (andel pasienter i live uten PSAstigning på et gitt evalueringstidspunkt) og prostataspesifikk overlevelse (pasientoverlevelse av prostatakreft i prosent), totaloverlevelse, bivirkninger og helseøkonomi.

Lavdoserate brakyterapi er også sammenliknet med publiserte funn ved radikal kirurgi eller ekstern strålebehandling, som er etablerte behandlingsmodaliteter. Bivirkninger ble vurdert ut fra lege- eller pasientbaserte opplysninger om gastrointestinale og/eller urogenitale funksjoner og, hvis angitt, skår på livskvalitet. 


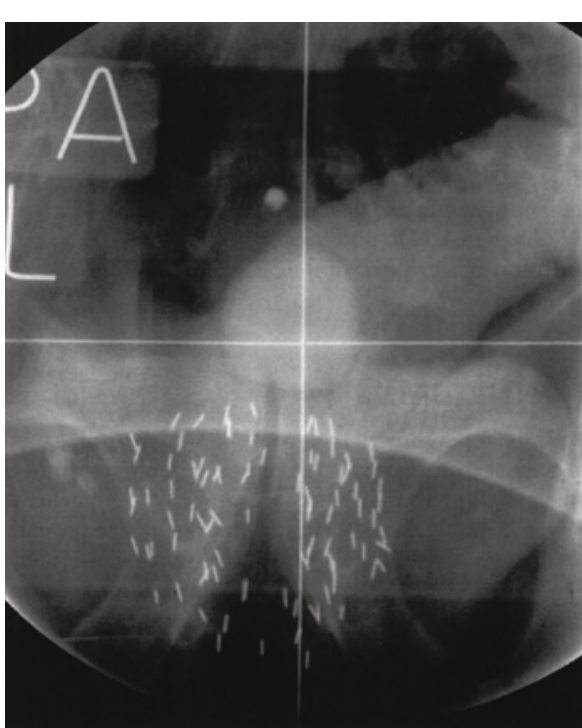

Figur 2 Radiologiskundersøkelseav bekkenet etter lavdoserate brakyterapi. Multiple radioaktive jodkorn er implantert permanent i prostatakjertelen. Pasienten er kateterisert og ballongen i blæren over symfysen synes tydelig. Foto: Bereich Interdisziplinäre Brachytherapie, Universitätsklinikum SchleswigHolstein, Campus Lübeck. Publisert med tillatelse fra dr. György Kovács

\section{Resultater}

\section{Effektmål}

Det finnes kun én publisert randomisert, kontrollert studie med lavdoserate brakyterapi. I den ble 200 pasienter ble randomisert til enten til lavdoseterapi eller radikal kirurgi (7). Primært effektmål var fem år PSA-fri overlevelse (91\% for kirurgi versus $91,7 \%$ for lavdoserate brakyterapi). Det var ingen forskjell i tilbakefall mellom gruppene. I Cochranes systematiske oversiktsanalyse ble denne studien sterk kritisert på grunn av metodiske svakheter. Peinemann og medarbeidere konstaterte at det var lite som tydet på behandlingsmessige fordeler med lavdoserate brakyterapi i forhold til radikal kirurgi og etterlyste flere randomiserte studier (18).

Flere behandlingssentre med lang erfaring med lavdoserate brakyterapi har publisert sine langtidsresultater (tab 1). Crook og medarbeidere har rapportert sine ti års erfaringer med lavdoseterapi hos 1111 pasienter ved Princess Margaret Hospital (10), der $965(86,9 \%)$ hadde lavrisikosykdom. PSAtilbakefall forekom hos $<2 \%$ av pasientene.

Taira og medarbeidere observerte svært gode langtidsresultater (PSA-fritt intervall) $\mathrm{i}$ sin studie med 1656 pasienter etter en median oppfølgingstid på sju år (12). I lavrisikogruppen var residivfri PSA-overlevelse $98,6 \%$ og prostataspesifikk overlevelse $99,8 \%$.

Morris og medarbeidere publiserte populasjonsbaserte resultater for 1006 pasienter i et kvalitetssikret brakyterapiprogram bestående av pasienter med både lav $(58 \%)$ og intermediær risiko $(42 \%)$ behandlet fra 1997 ved fem forskjellige sentre (16). Etter en median oppfølging på 7,5 år var estimert ti års PSA-fri overlevelse 94,1 \%

Zelefsky og medarbeidere har publisert en retrospektiv studie med 448 lavrisikoprostatakreftpasienter der sju års prostataspesifikk overlevelse var $95 \%$ i gruppen som fikk lavdoserate brakyterapi, versus $89 \%$ i gruppen som fikk ekstern strålebehandling med totaldose 81 Gy $(\mathrm{p} \leq 0,004)(13)$.

Kupelian og medarbeidere rapporterer i sin komparative analyse av 950 pasienter at de som fikk lavdoserate brakyterapi hadde en PSA-fri overlevelse på $83 \%$, de som fikk radikal kirurgi en overlevelse på $81 \%$ og de som fikk ekstern strålebehandling en overlevelse på $81 \%(\mathrm{p}<0,001)(5)$.

En retrospektiv kohortstudie med 41395 pasienter, med endepunkt prostatakreftspesifikk overlevelse og totaloverlevelse, der de med lav og intermediær risikoprofil var analysert sammen, viste, uavhengig av alder, ingen statistisk forskjell mellom lavdoserate brakyterapi og radikal kirurgi (19). Kollmeier og medarbeidere finner heller ingen forskjell mellom disse to behandlingsmodalitetene i sine langtidsresultater (15).

\section{Bivirkninger}

I flere studier rapporteres det at det er få langtidsbivirkninger etter lavdoserate brakyterapi når det gjelder ereksjonsevne og urininkontinens. I Buron og medarbeideres studie, som var basert på pasientopplysninger fra validerte spørreskjemaer, hadde $88 \%$ av pasientene med radikal kirurgi erektil dysfunksjon og 68,4\% anga urinlekkasje seks måneder etter behandling. Hos pasienter med lavdoserate brakyterapi, der 43,5\% hadde fått neoadjuvant androgen deprivasjonsterapi, rapporterte $50,8 \%$ om erektil dysfunksjon, mens bare $12,5 \%$ utviklet urinlekkasje (20).

I Stone \& Stocks studie hadde $75 \%$ av pasientene legerapportert ereksjonsevne før implantasjonen, mot $50 \%$ i oppfølgingstiden på minst fem år. Det var signifikant korrelasjon mellom alder og bevart ereksjonsevne. Urininkontinens forekom hos $1,2 \%(21)$.

I en annen rapport om langtidsbivirkninger fem år etter lavdoserate brakyterapi ble pasientenes selvrapporterte livskvalitet og seksualfunksjon analysert. Grad 2-komplikasjoner fra urinveier og rectum forekom hos henholdsvis $5 \%$ og $2,9 \%$, mens $37,1 \%$ hadde erektil dysfunksjon (22).

I en amerikansk retrospektiv studie med 729 lavrisikopasienter fant man, basert på legerapporterte bivirkninger, at behandling med lavdoserate brakyterapi $(n=448)$ førte til økt forekomst av urinveis- og rectumplager grad $2(15,6 \%$ og 5,1\%), men det var færre med erektil dysfunksjon enn etter ekstern strålebehandling (35\% versus $44 \%$ ) $(\mathrm{n}=281)$ (13).

Etter lavdoserate brakyterapi er det få rektale langtidsproblemer, og de opptrer oftest innen de første to år som blødning ved defekasjon. Phan og medarbeidere rapporterer om grad 2-blødning hos 3,7\% og grad 3 hos $0,4 \%(23)$.

I en nederlandsk studie har man i 20 år observert 232 pasienter med prostatakreft som utviklet primærcancer i urinblære og rectum i forløpet etter lavdoserate brakyterapi eller kirurgi. Det var ingen forskjell i insidens mellom de to behandlingene, heller ikke ved sammenlikning med insidensen $\mathrm{i}$ normalbefolkningen (8).

\section{Helseøkonomi}

En fransk gruppe publiserte i 2007 helseøkonomiske sammenlikninger mellom radikal kirurgi og lavdoserate brakyterapi (20). Det ble ikke funnet signifikante forskjeller i kostnader mellom behandlingsmetodene. NICE-instituttet har i sine kostnad-nytte-vurderinger av lavdoserate brakyterapi ansett denne metoden som økonomisk likeverdig med radikal kirurgi og ekstern strålebehandling hos lavrisikopasienter med prostatakreft (24). Wilson og medarbeidere påpekte imidlertid at man burde se kostnadene i form av påløpende utgifter etter intervensjonene (25). Her kom lavdoserate brakyterapi likeverdig ut $i$ en kostnad-nytte-analyse sammenliknet med radikal kirurgi.

Senter for medisinsk metodevurdering rapporterer at lavdoserate brakyterapi synes å være omtrent på samme kostnadsnivå som de alternative behandlingsvalg radikal kirurgi og ekstern strålebehandling (26). Det kan imidlertid ikke ses at kostnadene ved sykefravær og transportutgifter ved poliklinisk behandling er inkludert i rapporten.

\section{Diskusjon}

Vår litteraturgjennomgang viser at langtidsresultatene etter lavdoserate brakyterapi er ekvivalente med resultatene etter radikal kirurgi og ekstern strålebehandling. Ved NICE-instituttet anser man lavdoserate brakyterapi som etablert behandling, med resultater på linje med de to andre ved lavrisiko prostatakreft.

De europeiske organisasjoner for strålebehandling (ESTRO), for forskning og kreftbehandling (EORTC) og av urologer (EAU) utga i 2010 kliniske retningslinjer for lavdoserate brakyterapi hos pasienter med prostatakreft med lav risikoprofil der ekstraprostatisk ekstensjon av tumor var utelukket (27). I EAUs retningslinjer for 2012 anbefales lavdoserate brakyterapi til prostatakreft- 
Tabell 1 Én randomisert ${ }^{1}$ og 11 ikke-randomiserte studier med over 100 inkluderte pasienter behandlet med lavdoserate brakyterapi

\begin{tabular}{|c|c|c|c|c|c|}
\hline Førsteforfatter, år (referanse) & Antall pasienter & PSA-fri overlevelse (\%) & $\begin{array}{c}\text { Prostataspesifikk } \\
\text { overlevelse (\%) }\end{array}$ & $\begin{array}{c}\text { Median } \\
\text { oppfølgingstid (md.) }\end{array}$ & Evidensgrad \\
\hline Kupelian P, 2004 (5) & 950 & 75,0 & & 56 & 3 \\
\hline Merrick G, 2005 (6) & 119 & 96.1 & & 82 & 3 \\
\hline Giberti C, 2009 (7) 1 & 200 & 91,7 & & 60 & $1 b$ \\
\hline Hinnen K, 2011 (8) & 232 & 88,0 & 96,0 & 69 & 3 \\
\hline Prada P, 2010 (9) & 734 & 92,0 & & 55 & 3 \\
\hline Crook J, 2011 (10) & 965 & 97,2 & 95,0 & 42 & 3 \\
\hline Sylvester J, 2011 (11) & 128 & 85,9 & 80,4 & 139 & 3 \\
\hline Taira A, 2011 (12) & 1656 & 98,6 & 99,8 & 84 & 3 \\
\hline Zelefsky M, 2011 (13) & 448 & 95,0 & & 77 & $2 b$ \\
\hline Dickinson P, 2014 (14) & 1038 & 94,2 & & 60 & 3 \\
\hline Kollmeier M, 2013 (15) & 178 & 97,0 & & 83 & 3 \\
\hline Morris W, 2013 (16) & 1006 & 94,1 & 99,1 & 89 & 3 \\
\hline
\end{tabular}

pasienter i lavrisikogruppen (3). I de land hvor metoden anvendes, er dette ansett som standardbehandling (28). EAU bedømmer datagrunnlaget på evidensnivå $2 b$ (kunnskap som bygger på minst én godt utformet studie uten randomisering). I Norge anses lavdoserate brakyterapi som sidestilt med radikal kirurgi i det nasjonale handlingsprogrammet for behandling av prostatakreft (17).

Målsettingen ved lavdoserate brakyterapi er lokal sykdomskontroll, reduksjon av risikoen for metastaser og bibehold av god livskvalitet. På grunn av god prognose er bivirkninger og livskvalitet hos pasientene og deres preferanser helt sentrale elementer ved metoden $(27,28)$. Pasientene må selekteres grundig for å opprettholde lav morbiditetsprofil.

For å hindre overbehandling bør det foreligge retningslinjer for oppstart av behandling, både ved diagnose og ved progrediering under aktiv overvåking. Imidlertid er kriteriene for å selektere og monitorere disse pasientene ikke klare. Vi har derfor konsentrert oss om dem som ønsker en målrettet primærbehandling. Risikoen for at primærtumor underestimeres og underbehandles er også til stede, slik det ble påvist i en randomisert studie der pasienter under aktiv overvåking hadde signifikant redusert prostataspesifikk overlevelse sammenliknet med dem som hadde hatt radikal kirurgi (21).

I vårt litteratursøk fant vi at det er sparsomme bivirkninger etter lavdoserate brakyterapi. Pasienter med obstruktive vannlatingsproblemer er uegnet for behandlingen - symptomene forsterkes. De bør tilbys annen kurativ behandling. Risikoen for sekundær- cancer i rectum eller urinblære er ikke økt i forhold til risikoen i normalbefolkningen, slik at behandling av unge pasienter ikke synes å være kontraindisert (8).

Internasjonale randomiserte undersøkelser med lavdoserate brakyterapi er ikke utført, og det er usannsynlig at slike blir implementert $(29,30)$. Dette er betinget av prostatakreftens biologi. Residivfrekvensen hos lavrisikopasienter er lav, og sannsynligheten for å få signifikante forskjeller etter 15-20 års oppfølging er liten. Pasientenes behandlingspreferanser for øvrig kan dessuten gjøre randomisering vanskelig (31).

Lavdoserate brakyterapi er et attraktivt kurativt behandlingsalternativ på grunn av få bivirkninger. Metoden er standardbehandling i Europa og USA for organlokalisert lavrisikoprostatakreft.

Det foreligger kostnad-nytte-vurderinger som tilsier at lavdoserate brakyterapi er sidestilt med radikal kirurgi og ekstern strålebehandling $(9,26)$, men det synes ikke som om sykefravær og omkostninger ved pasienttransport er tatt med i beregningene. Behandlingen tar omtrent halvannen time, gjennomsnittlig sykehusopphold er 12 timer, og pasienten kan vanligvis begynne $i$ arbeid igjen etter 3-4 dager. Ved ekstern strålebehandling får pasientene poliklinisk behandling hver dag i omtrent åtte uker, med vanligvis åtte ukers etterfølgende sykefravær. Ifølge en nylig publisert studie er halvparten av pasientene sykmeldt i over seks uker etter radikal kirurgi (32).

Flere uroonkologer i Norge behersker teknikken med høydoserate brakyterapi (33, 34). Implantasjonsteknikken ved høydose- rate og lavdoserate brakyterapi er relativt identisk. I 2005 ble behandlingsbehovet for lavdoserate brakyterapi i Norge estimert til ca. 60-70 pasienter (intern rapport utgående fra faggruppe ved Radiumhospitalet). Men på grunn av økt oppmerksomhet omkring prostatakreft og økende villscreening vil insidensen av lavgradig sykdom også hos yngre menn øke. Dette vil sannsynligvis medføre at det fremtidige behov for lavdoserate brakyterapi vil bli større.

Introduksjon av metoden vil fra et medisinskfaglig synspunkt være fremtidsrettet. Hvis sykefravær og pasienttransport tas med, mener vi at lavdoserate brakyterapi vil gi samfunnsøkonomiske besparelser i forhold til annen behandling.

\section{Konklusjon}

Lavdoserate brakyterapi, eller innvendig strålebehandling, er en effektiv og sikker kurativ behandlingsopsjon for pasienter med lokalisert prostatakreft med lav risikoprofil. Vårt litteratursøk viser likeverdige langtidsresultater med prostatektomi og ekstern strålebehandling, dermed kan flesteparten av pasientene bli spart for langvarige bivirkninger.

Randomiserte studier med totaloverlevelse som endepunkt er imidlertid ikke utført. Risikoen for urininkontinens og erektil dysfunksjon er lavere enn etter ekstern strålebehandling og prostatektomi. På grunn av kort behandlingstid, få bivirkninger og kort sykmeldingsperiode synes metoden å være kostnadseffektiv. 


\section{Nils Kristian Raabe (f. 1946}

er dr.med., spesialist i onkologi og i indremedisin og overlege. Han har spesialkompetanse innen uroonkologi og høydoserate brakyterapi av prostata og er pensjonert fra Oslo universitetssykehus, Radiumhospitalet.

Forfatter har fylt ut ICMJE-skjemaet og oppgir ingen interessekonflikter.

\section{Marius Normann (f. 1972)}

er spesialist i onkologi, med spesialkompetanse innen høydoserate brakyterapi av prostata og gynekologisk kreft. Han er fagansvarlig onkolog ved Aleris.

Forfatter har fylt ut ICMJE-skjemaet og oppgir ingen interessekonflikter.

\section{Wolfgang Lilleby (f. 1964)}

er dr.med., spesialist i onkologi, med spesialkompetanse innen fagfelt uroonkologi og høydoserate brakyterapi av prostata, og overlege. Han er engasjert i innovativ medisin, translasjonsforskning og kliniske studier.

Forfatter har fylt ut ICMJE-skjemaet og oppgir ingen interessekonflikter.

\section{Litteratur}

1. Cancer in Norway 2011. Oslo: Kreftregisteret, 2011. www.kreftregisteret.no/en/General/News/ Cancer-in-Norway-2011/ (25.11.2014).

2. Kvåle R, Møller B, Angelsen A et al. Regional trends in prostate cancer incidence, treatment with curative intent and mortality in Norway 1980-2007. Cancer Epidemiol 2010; 34: 359-67.

3. Heidenreich A, Bellmunt J, Bolla M et al. EAU guidelines on prostate cancer. Part I: screening. diagnosis, and treatment of clinically localised disease. Actas Urol Esp 2011: 35: 501-14.

4. Raabe NK, Lilleby W, Tafjord G. Høydoserate brakyterapi ved prostatakreft i Norge. Tidsskr Nor Legeforen 2008; 128: 1275-8.

5. Kupelian PA, Potters L, Khuntia D et al Radical prostatectomy, external beam radiotherapy $<72$ Gy, external beam radiotherapy $>$ or $=72 \mathrm{~Gy}$, permanent seed implantation, or combined seeds/ external beam radiotherapy for stage T1-T2 prostate cancer. Int J Radiat Oncol Biol Phys 2004: 58: 25-33

6. Merrick GS, Butler WM, Wallner KE et al. Impact of supplemental external beam radiotherapy and/ or androgen deprivation therapy on biochemical outcome after permanent prostate brachytherapy. Int J Radiat Oncol Biol Phys 2005; 61: 32-43.
7. Giberti C, Chiono L, Gallo F et al. Radical retropubic prostatectomy versus brachytherapy for low-risk prostatic cancer: a prospective study. World J Urol 2009; 27: 607-12

8. Hinnen KA, Schaapveld M, van Vulpen $M$ et al. Prostate brachytherapy and second primary cancer risk: a competitive risk analysis. J Clin Oncol 2011: 29: 4510-5

9. Prada PJ, Juan G, González-Suárez H et al. Prostate-specific antigen relapse-free survival and side-effects in 734 patients with up to 10 years of follow-up with localized prostate cancer treated by permanent iodine implants. BJU Int 2010; 106: 32-6

10. Crook J, Borg J, Evans A et al. 10-year experience with I-125 prostate brachytherapy at the Princess Margaret Hospital: results for 1,100 patients. Int J Radiat Oncol Biol Phys 2011; 80: 1323-9.

11. Sylvester JE, Grimm PD, Wong J et al. Fifteen-year biochemical relapse-free survival, cause-specific survival, and overall survival following I(125) prostate brachytherapy in clinically localized prostate cancer: Seattle experience. Int J Radiat Oncol Bio Phys $2011 ; 81: 376-81$

12. Taira AV, Merrick GS, Butler WM et al. Long-term outcome for clinically localized prostate cancer treated with permanent interstitial brachytherapy. Int J Radiat Oncol Biol Phys 2011; 79: 1336-42.

13. Zelefsky MJ, Yamada Y, Pei X et al. Comparison of tumor control and toxicity outcomes of high-dose intensity-modulated radiotherapy and brachytherapy for patients with favorable risk prostate cancer. Urology 2011; 77: 986-90.

14. Dickinson P, Malik J, Mandall P et al. Five-year outcomes after iodine-125 seed brachytherapy for low-risk prostate cancer at three cancer centres in the UK. BJU Int 2014; 113: 748-53.

15. Kollmeier MA, Fidaleo A, Pei X et al. Favourable long-term outcomes with brachytherapy-based regimens in men?60 years with clinically localized prostate cancer. BJU Int 2013; 111: 1231-6.

16. Morris WJ, Keyes M, Spadinger I et al. Populationbased 10-year oncologic outcomes after low-doserate brachytherapy for low-risk and intermediaterisk prostate cancer. Cancer 2013: 119: 1537-46.

17. Helsedirektoratet. Nasjonale retningslinjer. Hand lingsprogram for prostatakreft. Oslo: Helsedirektoratet, 2013

18. Peinemann F, Grouven U, Bartel $C$ et al. Permanent interstitial low-dose-rate brachytherapy for patients with localised prostate cancer: a systematic review of randomised and nonrandomised controlled clinical trials. Eur Urol 2011; 60 : $881-93$.

19. Tward JD, Lee CM, Pappas LM et al. Survival of men with clinically localized prostate cancer treated with prostatectomy, brachytherapy, or no definitive treatment: impact of age at diagnosis. Cancer 2006; 107: 2392-400

20. Buron C, Le Vu B, Cosset JM et al. Brachytherapy versus prostatectomy in localized prostate cancer: results of a French multicenter prospective medico-economic study. Int J Radiat Oncol Biol Phys 2007; 67: 812-22.
21. Stone NN, Stock RG. Long-term urinary, sexual, and rectal morbidity in patients treated with iodine-125 prostate brachytherapy followed up for a minimum of 5 years. Urology 2007; 69: 338-42.

22. Rodriques G, Yao X, Loblauw DA, Brundage $M$, et al. Low-dose rate brachytherapy for patients with low- or intermediate-risk prostate cancer: a systematic review. Can Urol Assoc J 2013; 7: 463-70.

23. Phan J, Swanson DA, Levy LB et al. Late rectal complications after prostate brachytherapy for localized prostate cancer: incidence and management. Cancer 2009: 115: 1827-39.

24. National Institute for Health and Care Excellence. NICE guidelines CG58. London: NICE publication, 2014. www.nice.nhs.uk/guidance/ index.jsp?action $=$ bylD\&o=11924 $(25.11 .2014)$

25. Wilson LS, Tesoro R, Elkin EP et al. Cumulative cost pattern comparison of prostate cancer treatments. Cancer 2007; 109: 518-27.

26. Norderhaug I, Johansen TB, Dahl 0 et al. Brakyterapi ved prostatakreft. Tidsskr Nor Laegeforen 2002; 122: 2795-8.

27. Ash D, Flynn A, Battermann J et al. ESTRO/EAU/ EORTC recommendations on permanent seed implantation for localized prostate cancer. Radiother Oncol 2000; 57: 315-21.

28. Rosenthal SA, Bittner NHJ, Beyer DC et al. Ameri can Society for Radiation Oncology (ASTRO) and American College of Radiology (ACR) practice guideline for the transperineal permanent brachytherapy of prostate cancer. Int J Radiat Oncol Biol Phys 2011; 79: 335-41.

29. Crook JM, Gomez-Iturriaga A, Wallace $K$ et al. Comparison of health-related quality of life 5 years after SPIRIT: Surgical Prostatectomy Versus Interstitial Radiation Intervention Trial. J Clin Oncol 2011; 29: 362-8.

30. Cosset JM, Barret E, Castro-Pena P et al. Onestep customized transurethral resection of the prostate and permanent implant brachytherapy for selected prostate cancer patients: technically feasible but too toxic. Brachytherapy 2011; 10 : 29-34.

31. Wilt TJ. Can randomized treatment trials in early stage prostate cancer be completed? Clin Oncol (R Coll Radiol) 1998; 10: 141-3.

32. Dahl S, Steinsvik EA, Dahl AA et al. Return to work and sick leave after radical prostatectomy: a prospective clinical study. Acta Oncol 2014: 53 . $744-51$.

33. Raabe NK, Tafjord T, Lilleby W. Høydoserate brakyterapi, ekstern strålebehandling og androgen deprivasjon ved cancer prostatae. Tidsskr Nor Legeforen 2012: 132. http://tidsskriftet.no/ raabeappendiks (25.11.2014).

34. Lilleby W. Tafjord G, Raabe NK. Implementation of high-dose-rate brachytherapy and androgen deprivation in patients with prostate cancer. Int J Radiat Oncol Biol Phys 2012; 83: 933-9.

Mottatt 25.10. 2013, første revisjon innsendt 14.4 . 2014, godkjent 25.11. 2014. Redaktør: Sigurd Høye. 